\title{
MEMUDARNYA WIBAWA NINIAK MAMAK SEBAGAI URANG NAN GADANG BASA BATUAHDI MINANGKABAU
}

\author{
Teguh Haniko Putra \\ Program Pascasarjana \\ Institut Seni Indonesia Surakarta \\ JI. Ki Hadjar Dewantara No. 19 Kentingan, Jebres, Surakarta, 57126
}

\section{Rahayu Supanggah}

ISI Surakarta

\begin{abstract}
ABSTRAK
Gadang, basa, batuah. Demikianlah niniak mamak di Minangkabau. Gadang berarti orang yang dituakan dan jadi panutan dalam kaumnya. Basa berarti menjadi pemimpin dan pengatur dalam sukunya. Batuah mengandung arti sebagai orang yang bijaksana, segala perbuatan dan ucapannya menjadi acuan sehingga sangat dihormati dalam nagari. Niniak mamak bukan hanya sekedar gelar yang disematkan kepada seseorang. Lebih dari sekedar gelar, niniak mamak adalah tampuk pimpinan adat dan tiang penyangga dalam nagari. Orang yang teguh dalam berpendirian, berprinsip dalam bersikap, konsisten dalam bicara, dan bertanggung jawab dalam bertindak. Betapa pentingnya peranan niniak mamak dalam tatanan adat Minangkabau dan betapa besarnya tanggung jawab niniak mamak dalam membina, mengayomi dan menuntun anak kemenakan, serta mengatur pemanfaatan harta pusaka tinggi dan tanah warisan kaum untuk anak kemenakannya.
\end{abstract}

Kata kunci: Niniak mamak, pemimpin, Minangkabau.

\begin{abstract}
Gadang, basa, batuah. Tuladnya niniak mamak in Minangkabau. Gadang means a person who becomes a leader and regulator in his family. The term means being a leader and regulator in his tribe. The capital is meaningful as a wise man, his deeds and his speech become a form of honor that is so respected in the country. Niniak mamak is not merely a title that is pinned to a person. More than just a degree, the mamak is a leader of the indigenous leaders and the pillars in the nagari. People who stand firm in the stand, are principled in being consistent, consistent in speech, and responsible in acting. How important is the role of mamak in the Minangkabau customary order and how much of the responsibility of the mamak in building, protecting and guiding the nephews, and regulating the utilization of high estate and racial heritage land for their nephews.
\end{abstract}

Keywords: Niniak mamak, leader, Minangkabau.

\section{A. Pengantar}

Minangkabau merupakan salah satu etnik yang ada di Nusantara, etnik yang mempunyai sistem kekerabatan matrilineal atau kekerabatan menurut garis keturunan ibu, yang mana hal ini sangatlah berbeda dari mayoritas masyarakat dunia yang menganut pola patrilineal atau kekerabatan menurut garis keturunan ayah. Berbicara mengenai sejarah Minangkabau, tidaklah mudah untuk menentukan awal sejarah dari suku ini. Karena tidak adanya catatan sejarah yang valid mengenai petunjuk tentang sistem pemerintahan yang demokratis dan masyarakatnya yang matrilineal seperti yang dikenal pada saat ini. Sejarah diwariskan turun temurun secara lisan melalui kisah tambo atau cerita rakyat yang biasa dikenal dengan istilah kaba. Sejarah itupun hanya mengisahkan peristiwa dan waktu secara samar-samar, oleh karena cara penyampaiannya yang secara lisan, kaba sangat rentan terhadap bumbu-bumbu dari pencerita agar ceritanya semakin menarik untuk disimak, sehingga kisah tambo atau cerita rakyat itu mengandung banyak versi sesuai dengan keperluan pencerita dan kehendak dari pendengarnya.

Wilayah Minangkabau menurut Ibrahim Dt. Sanggono Diradjo (2009:1), dari tutua nan badanga, warih nan bajawek sarato tulih nan babaco (tutur yang didengar, waris yang diterima dan tulisan yang dibaca) serta dari beberapa perpustakaan wilayah Minangkabau itu digambarkan ialah di sekitar Gunung Merapi, Gunung Sago, Gunung Singgalang, sampai ke Gunung Talang, Gunung Kerinci, serta ke Gunung Pasaman. Dalam barih balabeh ${ }^{1}$ Minangkabau disebutkan: 
Mano nan alam Minangkabau Nan salilik Gunuang Marapi Saedaran Gunuang Pasaman Sajajaran Sago jo Singgalang Saputaran Talang jo Kurinci

Terjemahan dalam Bahasa Indonesia:

Yang mana alam Minangkabau

Yang selingkar Gunung Merapi Sekitar Gunung Pasaman

Sejajaran Gunung Sago dan Gunung Singgalang

Seputar Gunung Talang dan Gunung Kerinci

Masih menurut Ibrahim Dt. Sanggono Diradjo, pembatasnya disebutkan berupa nagari ${ }^{2}$ atau bentuk pemukiman dan keadaan alam yang terdekat ke perbatasan. Pembatas-pembatas tersebut berbunyi dalam barih balabeh sebagai berikut.

Dari Sirangkak Nan Badangkang

Hinggo Buayo Putiah Daguak

Sampai ka Pintu Rajo llia

Sampai ka Durian Ditakuak Rajo

Sipisau-pisau Anyuik

Sialang Balantak Basi

Hinggo Ayia Babaliak Mudiak Sampai ka Ombak Nan Badabua Sikilang jo Aia Bangih Hinggo Lauik Nan Mandidiah

Cubadak jo Rao Mapat Tunggua

Pasisia Banda Sapuluah

Hinggo Taratak Aia Itam

Sampai ka Tanjuang Simalidu

Pucuak Jambi Sambilan Lurah

Terjemahan dalam bahasa Indonesia:

Dari Sirangkak nan Badangkang

Hingga Buayo Putiah Daguak

Sampai ke Pintu Rajo llia

Sampai ke Durian Ditakuak Rajo

Sipisau-pisau Anyuik

Sialang Balantak Basi

Hingga Ayia Babaliak Mudiak

Sampai ke Omban nan Badabua

Sikilang dan Ayia Bangih

Hingga laut yang mendidih

Ke timur arah Gununga Malintang
Cubadak dengan Rao Mapat Tunggua

Pasisia Banda Sapuluah

Hingga Taratak Ayia Itam

Sampai ke Tanjung Simalidu

Pucuak Jambi Sambilan Lurah)

Jika diperkirakan tempat-tempat batasan itu melalui peta saat ini dapat digambarkan sebagai berikut.

- Perkiraan di sebelah utara ialah dari Ranah Air Bangis, arah ke Tiur ke Silapiang, Gunung Malintang, Paraman Ampalu, Cubadak, Rao Mapat Tunggul, Sialang, terus ke Gunung Sailan dan Singingi, sampai bertemu dengan ranah yang sungainya sudah terpengaruh oleh pasang surut air laut di sebelah timur.

- Perkiraan batas di sebelah timur ialah Gunung Sailan, Sipisau-pisau Anyuik, Inderagiri, Tanjung Simalidu, Durian Ditakuak Rajo, dan berbatas dengan Jambi.

- Perkiraan batas di sebelah selatan ialah dengan Sapucuak, Jambi Sambilan Lurah, Rejang Lebong, Bengkulu (Pintu Rajo llia), Inderagiri (Buayo Putiah Daguak), sampai ke Lautan Hindia (ombak nan badabua).

- Perkiraan batas di sebelah barat ialah dari Bengkulu dan Indrapura, dari selatan ke utara termasuk Pesisir Selatan (Banda Sapuluah) sampai ke Sikilang dan Air Bangis sampai ke air laut yang putih seperti mendidih.

Itulah gambaran wilayah Minangkabau dan sekaligus sebagai wilayah hukum adat Minangkabau.

Dalam tatanan kajian budaya, Minangkabau merupakan salah satu suku yang dikenal sebagai masyarakat yang unik karena memadukan nilai-nilai tradisi dengan agama (Islam) di dalam kehidupan bermasyarakatnya.

Hal ini tertuang dalam filosofi adat yang berbunyi:

adat basandi syarak,

syarak basandi kitabullah,

syarak mangato,

adat mamakai

Terjemahan dalam Bahasa Indonesia:

Adat berlandaskan agama (islam)

Agama (islam) berlandaskan Alqur'an

Agama memberi perintah

Adat menerapkan 


\section{GEEAR Jumal sai isudya}

Filosofi diatas mengandung makna bahwa sumber dasar dari adat adalah hukum Islam, sedangkan hukum Islam sumber dasarnya adalah Alqur'an. Pandangan ini menempatkan Islam sebagai sumber utama dalam pandangan hidup masyarakat Minangkabau. Menurut sejarah, kedatangan Islam ke Minangkabau tidaklah melalui kekuasaan atau penaklukan. Islam masuk ke Minangkabau dibawa oleh pedagang dari Arab, tetapi penyebaran Islam dilakukan oleh orang Minangkabau sendiri setelah mereka pergi merantau ke Aceh bahkan ke negeri Arab. Secara filosofis, ajaran islam mengandung banyak persamaan dengan falsafah masyarakat Minangkabau, yakni alam takambang jadi guru. Islam juga memandang manusia dalam kedudukan yang sama antara sesamanya, baik dalam hak maupun dalam kewajiban.

Adat dalam istilah yang jeneral merupakan gagasan kebudayaan yang terdiri dari nilai-nilai kebudayaan, norma, kebiasaan, kelembagaan, dan hukum yang lazim dilakukan di suatu daerah. Apabila adat ini tidak terlaksana, maka akan terjadi kerancuan yang menimbulkan sanksi yang tidak tertulis oleh masyarakat setempat terhadap pelaku yang dianggap menyimpang. Di Minangkabau, adat terbagi dalam empat katagori:

1. Adat Nan Sabana Adat (Adat yang sebenarnya)

lalah adat yang asli, yang baku dan tidak bisa dirubah. Sesuatu yang tidak dipengaruhi tempat, waktu dan keadaan. Adat ini bersumber dari Alqur'an, hadist nabi Muhammad SAW, dan dari alam sehingga lahirlah pepatah alam takambang jadi guru (alam terbentang jadi guru). Seperti yang tertuang dalam falsafah Minangkabau:

\section{Adat nan sabana adat Indak lapuak dek hujan Indak lakang dek paneh \\ Kok dicabuik indak mati \\ Kok diasak indak layua \\ Adat basandi syarak \\ Syarak basandi kiabullah \\ Syarak mangato \\ Adat mamakai}

Terjemahan dalam Bahasa Indonesia:
Adat yang sebenar adat
Tidak lapuk oleh hujan
Tidak lekang oleh panas
Walau dicabut tidak mati
Walau dipindahkan tidak layu

Adat berlandaskan syarak

Syarak berlandaskan Alqur'an

Agama memberi perintah

Adat menerapkan

\section{Adat nan Diadatkan (Adat yang diadatkan)}

lalah sesuatu kebiasaan yang telah diambil melalui mufakat, seperti tata cara pernikahan. Adat ini dijadikan undang-undang dan hukum yang berlaku. Adat ini lahir dan diatur dengan mufakat dan disusun berdasarkan Adat nan sabana adat yang didukung dengan kesepakatan para pemuka adat.

\section{Adat nan Taradat (Adat yang teradat)}

lalah sesuatu yang sifatnya berubah-ubah sesuai dengan waktu, tempat dan keadaan. Maksudnya adalah peraturan yang dilahirkan oleh mufakat atau konsensus masyarakat yang memakainya. Adat ini adalah adat yang dipakai dalam suatu wilayah atau nagari, dengan kata lain adat yang teradat antara nagari yang satu dengan yang lain belum tentu sama. Ini termasuk adat salingka nagari (adat selingkar nagari). Pepatah Minangkabau mengatakan:

Dimano sumua digali, disitu rantiang dipatah Dimano bumi dipijak, disinan langik dijunjuang

Dimano nagari dihuni, disinan adat di pakai

Terjemahan dalam Bahasa Indonesia:

Dimana sumur digali, disitu ranting dipatah Dimana bumi dipijak, disana langit dijunjung Dimana nagari dihuni, disana adat dipakai)

Adat nan taradat tidak boleh bertentangan dengan Adat nan sabana adat maupun dengan Adat nan diadatkan. Justru harus memperkuat kedua adat tersebut. Adat ini tidak bisa dirubah kecuali ada kesepakatan melalui mufakat antara niniak mamak dengan masyarakat. Dengan kata lain, niniak mamak tidak bisa memutuskan sendiri untuk mengubah adat ini meskipun dia seorang pemimpin yang ikut serta menyepakati dalam pembentukan adat ini.

\section{Adat Istiadat}

Ialah sesuatu yang telah dilazimkan dalam suatu nagari atau kebiasaan yang berlaku di tengah masyarakat umum atau setempat. Seperti acara yang bersifat seremoni atau tingkah laku pergaulan baik itu berkomunikasi, bersilaturrahmi, berintegrasi dan bersosialisasi dalam masyarakat di suatu nagari. 
Minangkabau mempunyai satu masyarakat yang tersusun rapi dalam tatanan adat di bawah kepemimpinan para panghulu suku atau niniak mamak. Walaupun Minangkabau pernah jaya dibawah dinasti raja-raja Pagaruyuang, namun kerajaan itu adalah Negara yang berkonstistusi adat. Sedangkan raja tidak mutlak menyentuhkan tangan kekuasaannya yang menembus dominasi panghulupanghulu (niniak mamak) dalam nagari. Sistem kerajaannya berbentuk federasi, dimana penghulu berstatus sebagai raja-raja kecil yang berkuasa penuh dalam wilayah hukumnya masing-masing.

\section{B. Niniak mamak Sebagai Pemimpin Adat di Minangkabau}

Hidup dalam sebuah suku bangsa yang merupakan bagian dari dialektika peradaban juga tidak terlepas dari pentingnya kepemimpinan. Dalam masyarakat Minangkabau terdapat banyak suku yang diwariskan menurut garis keturunan ibu, dimana dalam setiap suku di pimpin oleh panghulu (niniak mamak) yang bergelar datuak. Sebagaimana yang disebutkan Ibrahim Dt. Sanggoeno Diradjo dalam bukunya Tambo Alam Minangkabau (2009:166) "Jabatan sebagai panghulu di peroleh seseorang karena diangkat oleh anggota kaumnya sendiri”. Datuak adalah gelar panghulu yang bersangkutan, sedangkan niniak mamak adalah himpunan panghulupanghulu dalam suatu nagari. Contoh Buyuang Datuak Rajo Sutan, panghulu dari suku Sikumbang, niniak mamak dari nagari Kambang.

Secara logat kata panghulu diambil dari dua patah kata yaitu pangkal dengan hulu, bermakna sebagai pemimpin dalam kaum. Pangkal artinya tampuk atau tangkai yang akan menjadi pegangan, sedangkan hulu artinya tempat awal keluar atau terbitnya sesuatu. Panghulu berarti tampuk tangkai yang mengarahkan, mengawasi dan pelindung bagi anak kemenakannya, serta tempat keluarnya aturan dan keputusan yang dibutuhkan masyarakat anak kemenakan yang dipimpinnya.

Kepemimpinan niniak mamak adalah kepemimpinan tradisional, sesuai pola yang telah digariskan adat secara berkesinambungan dalam kaum masing-masing, dalam suku dan nagari. Sesuai dengan fungsinya, maka dalam memilih seorang niniak mamak sudah sewajarnyalah memiliki kriteria umum sebagai seorang pemimpin. Seperti; loyal terhadap jabatan yang dimiliki, berilmu, jujur, adil, berani, tidak cacat moral, dan bertaqwa kepada Allah SWT. Niniak mamak mempunyai gaya kepemimpinan yang demokratis. Gaya demokratis disini maksudnya memberikan kebebasan dan keleluasaan kepada para bawahan dan pengikutnya untuk mengemukakan pendapatnya, saran dan kritikkannya dan selalu berpegang pada nilai-nilai demokrasi pada umumnya.

Adapun persyaratan khusus untuk menjadi seorang panghulu adalah; dipilih berdasarkan giliran menurut adat Bodi Chaniago, atau keturunan mamak kemenakan menurut adat Koto Piliang. Niniak mamak terpilih karena dianggap berilmu pengetahuan dan wawasan yang luas, mempunyai kemampuan dan kapabilitas, berwibawa, bertanggung jawab, disegani anak kemenakan serta berpendirian yang kokoh. Niniak mamak hendaklah teguh dalam berpendirian, berprinsip dalam bersikap, konsisten dalam bicara, dan bertanggung jawab dalam bertindak. Niniak mamak bertanggung jawab dan berkewajiban mengurusi dan menjalankan seluk beluk adat, memelihara, mengawasi serta menjaga anggota kaum, suku dan nagarinya.

Niniak mamak mengemban tanggung jawab yang sangat besar. Sebagai panghulu, beliau yang bertanggung jawab terhadap anak kemenakannya baik dalam mengayomi, melindungi, membina dan mengatur pemanfaatan harta pusaka tinggi dan tanah ulayat untuk anak kemenakannya, namun juga harus tetap menjalankan tugas dan tanggung jawabnya sebagai kepala keluarga bagi anak dan istrinya.

\section{Kaluak paku kacang balimbiang, ambiak tampuruang lenggang lenggokan \\ Bao manurun ka saruaso, tanamlah siriah di ureknyo Anak dipangku kamanakan di bimbiang, urang kampuang di patenggangkan Tenggang nagari jan binaso, tenggang sarato jo adatnyo}

Pepatah di atas mengandung arti bahwa seorang niniak mamak itu di samping memelihara anak-anaknya (kepala rumah tangga), juga harus membimbing kemenakan, serta menjaga nagari dan adat agar tidak binasa/punah dengan memperhatikan penerapan adat istiadat yang berlaku.

Niniak mamak merupakan tiang penyangga dalam kepemimpinan suku, dan sekaligus menjadi anggota dewan dalam pemerintahan nagari yang di sebut dengan Andiko. Andiko berasal dari bahasa sanskerta yaitu "andika" yang berarti memerintah (Ibrahim Dt. Sanggoeno Diradjo, 2009:166). Dalam pemerintahan nagari, niniak mamak lah yang bertugas untuk menyampaikan dan memperjuangkan 


\section{GEEAR Jumal sai isubya}

aspirasi kaum yang dipimpinnya serta menyelesaikan berbagai masalah yang timbul pada anak kemenakannya dalam nagari, seperti pepatah adat "Andiko di dalam kampuang, kusuik nan kamanyalasai, karuah nan kamampajaniah" (pemimpin di dalam kampung, kusut yang akan meluruskan, keruh yang akan menjernihkan). Sehingga nagari tanpa niniak mamak diibaratkan seperti negeri yang tidak bertuan karena tatanan adat yang dibuat tidak akan berjalan sebagaimana mestinya. Pepatah adat mengatakan "elok nagari dek pangulu, sumarak nagari dek rang mudo" (baik negeri karena penghulu, semarak negeri karena anak muda).

Dalam menyelesaikan segala persoalan anak kemenakan dalam hidup bermasyarakat, niniak mamak bermusyawarah dengan kaum ulama dan cadiak pandai (berilmu pengetahuan) serta pemerintahan nagari di balai adat yang disebut balerong dalam Kerapatan Adat Nagari (KAN). Karena setiap persoalan yang timbul dalam kaum, suku dan nagari dapat dicari pemecahannya melalui musyawarah dan mufakat. Hasil musyawarah mufakat inilah yang menjadi pedoman dalam menata kehidupan bermasyarakat.

Dalam kesatuan tugas, panghulu di sebut dengan "urang gadang nan basa batuah" yang berarti ; gadang dalam kaum, basa dalam suku, dan batuah dalam nagari. Gadang berarti dituakan dalam kaumnya, basa berarti besar dan menjadi panutan, pemimpin dan pengatur dalam sukunya, sedangkan batuah artinya bertuah, segala perbuatan dan ucapannya menjadi acuan dan sangat di hormati dalam nagari.

Dari penjabaran di atas dapat dilihat betapa pentingnya peranan niniak mamak dalam menjaga tatanan adat pada kehidupan masyarakat Minangkabau. Namun di era modernisasi seperti saat sekarang, arus budaya barat semakin kuat mempengaruhi pola pikir masyarakat yang berdampak pada kehidupan sosial dalam masyarakat. Kehidupan sosial yang dulu berdasarkan kebersamaan atau musyawarah tergeser menjadi individualis dan konsumeritis, lebih condong kepada memelihara kepentingan diri sendiri dari pada anggota masyarakatnya. Arus perubahan sosial yang cukup deras di era globalisasi ini juga sangat mempengaruhi wibawa kepemimpinan niniak mamak di tengah masyarakat. Dimana niniak mamak tidak bisa menghadang pengaruh yang dibawa bahkan banyak dari mereka ikut terbawa arus perubahan sehingga banyak yang terjangkit perilaku materialistis, haus kekuasaan dan individualistis. Sehingga hubungan kemenakan (masyarakat kaum) dengan mamak tidak lagi terjaga seperti seharusnya.

\section{Wibawa dan Kepemimpinan}

Menurut kamus besar Bahasa Indonesia, wibawa mempunyai dua pengertian: pertama, pembawaan untuk dapat menguasai dan mempengaruhi serta dihormati orang lain melalui sikap dan tingkah laku yang mengandung kepemimpinan dan penuh daya tarik, kedua adalah kekuasaan. Wibawa adalah hal yang sangat krusial yang harus dimiliki oleh seorang pemimpin. Dihormati atau tidaknya seorang pemimpin tergantung dari wibawa yang dimilikinya.

Manusia pada hakekatnya adalah makhluk sosial, dimana mereka saling membutuhkan antara satu dengan yang lainnya baik itu antara individu dengan individu, individu dengan kelompok maupun kelompok dengan kelompok. Rasa saling membutuhkan ini sudah tertanam dalam tiap individu manusia secara alami, sadar atau tidak sadar setiap manusia pasti akan membutuhkan manusia lainnya untuk bisa bertahan hidup. Namun Interaksi sosial dari beragam individu yang dilahirkan dengan berbagai macam watak dan kepribadian akan menimbulkan berbagai persoalan. Keberagaman yang memunculkan perbedaan inilah yang mengharuskan adanya sosok seorang pemimpin untuk pedoman dari setiap tindakan yang akan dilakukan untuk menghindari kesalahan dan menjaga keharmonisan sesama manusia. Pemimpin adalah bahagian terpenting dalam kehidupan kita sebab tanpa kepemimpinan, maka kita pun akan sulit menuju harapan serta tujuan yang dituju.

Pada dasarnya setiap manusia adalah pemimpin, yang membedakan antara satu dengan yang lain hanyalah besar lingkup kepemimpinan yang dijalankannya. Ada yang sebagai pemimpin dalam satu negara, dalam satu wilayah, dalam satu instansi bahkan sekurang-kurangnya sebagai pemimpin untuk dirinya sendiri. Perbedaan antara pekerjaan yang kacau dan pekerjaan yang berjalan dengan baik terletak pada kepemimpinan.

Kepemimpinan bisa terjadi apabila seseorang mampu mempengaruhi perilaku orang lain ke arah tercapainya suatu tujuan tertentu. Sebuah teori mengatakan bahwa kepemimpinan merupakan sebuah proses, bukan jabatan. Kepemimpinan adalah proses mempengaruhi sebuah kelompok yang terorganisasi untuk mencapai tujuan kelompok (Rich- 
ard L. Huges, Robert C. Ginnet, Gordon J. Curphy, 2012:6).

Sebagai unsur pokok kepemimpinan, kekuatan dan pengaruh seorang pemimpin merupakan aspek yang paling krusial yang menjadi barometer keberhasilan kepemimpinannya. Merujuk kepada kamus besar bahasa Indonesia (Balai Pustaka; 1988), kekuatan adalah tenaga, gaya atau kekuasaan. Sedangkan pengaruh adalah daya yang timbul dari sesuatu (orang, benda) yang ikut membentuk watak, kepercayaan atau perbuatan seseorang.

Pemimpin akan selalu berkorelasi dengan tanggung jawab, sebab tanggung jawab itu menjadi wilayah kekuasaan terhadap apa yang dipimpinnya. Pada dasarnya pemimpin bukanlah penguasa, namun kekuasaan mutlak harus dimiliki seorang pemimpin untuk menjalankan kepemimpinannya. Penguasa merupakan orang yang mempunyai kepentingan pribadi atau kelompok, menjadikan kepemimpinannya sebagai alat untuk mencapai kursi kekuasaan. Kalau kepentingan kekuasaan mengarah pada tendensi untuk menciptakan distorsi terhadap komunikasi, maka yang terjadi hanya ada penindasan dan reduksi (Rusmin Tumanggor, Kholis Ridho, $\mathrm{H}$. Nurrochim, 2010:40).

Pemimpin yang bijaksana menggunakan kekuasaan hanya sebagai sarana dalam melaksanakan kewajibannya, bukan menjadikan kekuasaan sebagai tujuan akhir dari kepemimpinan yang dijalankannya. Kekuasaan tidak digunakan sebagai modal untuk menguasai, tapi sebagai modal untuk memberikan yang terbaik dari kepemimpinannya.

\section{Potret Kesadaran Akan Gelar Niniak mamak}

Seiring dengan perkembangan zaman dan perubahan gaya hidup yang semakin individualis, berdampak kepada pola pikir masyarakat yang beranggapan bahwa peranan niniak mamak tidak lagi begitu berpengaruh dalam kehidupan seharihari. Pola pikir seperti ini mulai tumbuh dan berkembang sejak lahirnya undang-undang dari sistem ketatanegaraan, berlakunya pemerintahan desa menurut undang-undang no 5 tahun 1979 menetapkan desa sebagai unit pemerintahan terendah yang berlangsung selama lebih kurang 20 tahun telah merusak sosial masyarakat yang selama bernagari dulu terpelihara dengan baik karena sangat besarnya pengaruh niniak mamak dalam hidup bermasyarakat. Sistem pemerintahan terendah di Minangkabau tidak lagi mengindahkan keberagaman dan adat istiadat yang berlaku. Sentralistik pemerintahan berpusat dari atas, bukan lagi lahir dari bawah sesuai dengan nilai-nilai yang dianut masyarakat Minangkabau.

Selama kurun waktu 20 tahun kaum niniak mamak tidak difungsikan secara penuh dalam mengurus nagari, sehingga meruntuhkan pamor niniak mamak karena mereka tidak lagi mempunyai kekuasaan, kekuatan dan pengaruh yang seharusnya mereka miliki dalam menata kehidupan masyarakat, sehingga peranan niniak mamak mulai tergusur bahkan sudah mulai terlupakan. Karena sebagai unsur pokok kepemimpinan, kekuasaan, kekuatan dan pengaruh seorang pemimpin merupakan aspek yang paling krusial yang menjadi barometer keberhasilan kepemimpinannya.

Pada dasarnya pemimpin bukanlah penguasa, namun kekuasaan mutlak harus dimiliki seorang pemimpin untuk menjalankan kepemimpinannya. Penguasa merupakan orang yang mempunyai kepentingan pribadi atau kelompok, menjadikan kepemimpinannya sebagai alat untuk mencapai kursi kekuasaan. Kalau kepentingan kekuasaan mengarah pada tendensi untuk menciptakan distorsi terhadap komunikasi, maka yang terjadi hanya ada penindasan dan reduksi (Rusmin Tumanggor, Kholis Ridho, H. Nurrochim, 2010:40). Merujuk kepada kamus besar bahasa Indonesia (Balai Pustaka;1988), kekuatan adalah tenaga, gaya atau kekuasaan. Sedangkan pengaruh adalah daya yang timbul dari sesuatu (orang, benda) yang ikut membentuk watak, kepercayaan atau perbuatan seseorang.

Pertanyaanya, apa yang menyebabkan pudarnya wibawa niniak mamak sebagai uarang nan gadang basa batuah dalam masyarakat Minangkabau, sehingga niniak mamak hanya dipandang sebagai gelar yang disematkan kepada seseorang namun tidak lagi mempunyai pengaruh yang signifikan terhadap masyarakat yang dipimpinnya. Tapi, apakah benar niniak mamak sudah tidak lagi mempunyai pengaruh di tengah masyarakat Minangkabau? Mungkin lebih tepatnya, masyarakat tidak lagi mengindahkan betapa besarnya pengaruh niniak mamak dalam tatanan adat masyarakat Minangkabau.

Banyak faktor yang mempengaruhi wibawa niniak mamak ditengah masyarakat. Ada faktor internal yang muncul dari kepribadian niniak mamak itu sendiri, ada juga faktor eksternal dari lingkungan. Namun faktor yang paling mempengaruhi wibawa 


\section{GEEAR Jumal Sari Bublya}

niniak mamak di tengah masyarakat adalah kondisi dari adat itu sendiri. Adat yang tidak lagi dipertimbangkan masyarakat sehingga kehilangan potensi untuk menata kehidupan masyarakat yang semakin modern.

Bermula dari sistem ketatanegaraan dengan diterapkannya Undang-Undang no 5 tahun 1979 yang menghilangkan status nagari dan menetapkan desa sebagai unit pemerintahan terendah, secara tidak langsung mematikan fungsi niniak mamak sebagai pemimpin informal dalam nagari. Nagari adalah satu kesatuan masyarakat hukum adat di Minangkabau yang mempunyai batasan alam yang jelas dan aturanaturan tersendiri yang berbeda dengan pemerintahan desa administratif pada umumnya. Setelah reformasi, lahirlah Undang-Undang No 22/1999 tentang otonomi daerah yang memberikan angin segar kepada masyarakat Minangkabau dengan mengembalikan istilah nagari sebagai unit pemerintahan terendah. Undang-Undang itu ditindak lanjuti dengan Peraturan Daerah Sumbar No 9/2000 tentang ketentuan pokok pemerintahan nagari dan diubah dalam Perda Provinsi Sumbar no 2/2007 tentang Pemerintahan Nagari. Namun hal ini ternyata tidak serta merta mengembalikan hakekat dan semangat bernagari itu sendiri. Ini terlihat dari peranan niniak mamak ditengah masyarakat yang seperti mati suri.

Meskipun sistem ketatanegaraan telah mengembalikan kekuasaan pemerintahan ke daerah dengan istilah babaliak ka nagari (kembali ke nagari), namun sosok niniak mamak tidak lagi memiliki pamor seorang "andiko" atau pemimpin seperti tempo dulu. Sangat jarang terlihat niniak mamak memperjuangkan keluhan masyarakat tentang harga sembako yang semakin hari semakin mahal atau bersidang di Balairong untuk memusyawarahkan kalau seandainya ada peraturan dari pemerintahan pusat yang memberatkan masyarakat nagari. Sebab segala bentuk aspirasi rakyat angkat ditampung di lembaga Dewan Perwakilan Rakyat tingkat daerah. Segala bentuk tindak kriminalitas atau kenakalan remaja dan penyakit masyarakat, tidak lagi menjadi tanggung jawab penuh seorang niniak mamak, karena segala sesuatu yang berhubungan dengan hukum adalah wewenang polisi sebagai lembaga penegak hukum. Bahkan perkawinan yang melanggar adat seperti perkawinan sasuku (satu suku) tidak lagi mampu digagalkan niniak mamak selaku pemimpin adat karena permasalahan perkawinan bisa diselesaikan di KUA.

Keadaan ini semakin diperparah dengan kurangnya ilmu pengetahuan dan wawasan kemasyarakatan yang dimiliki oleh niniak mamak yang berkaitan dengan tugas-tugasnya di lapangan, bahkan makin banyak ditemui niniak mamak yang tidak paham tentang adat dengan segala seluk beluknya, bahkan adat yang berlaku di wilayah yang dipimpinnya. Sehingga dengan ketidak tahuannya menyebabkan kesenjangan dalam mengambil kebijaksanaan. Akhirnya gelar niniak mamak tidak lebih dari sekedar simbol atau bahkan hanya dianggap sebagai pelengkap tatanan adat.

Pentingnya peranan niniak mamak dalam lingkungan adat Minangkabau, mengharuskan niniak mamak harus memahami dan sangat mengerti dengan tatanan adat Minangkabau. Karena seorang niniak mamak yang tidak paham dengan adat istiadat, sama halnya seperti seorang hakim yang tidak mengerti dengan Undang-Undang. Niniak mamak sebagai urang nan gadang basa batuah ditengah masyarakat, sewajarnyalah memiliki pengetahuan yang luas, khususnya dibidang adat, sehingga apa pun permasalahan yang terjadi dalam nagari bisa di selesaikan di Lembaga Adat tanpa harus membawanya ke Pengadilan Negeri yang merupakan instansi pemerintah yang semestinya tidak berwenang dalam menyelesaikan permasalahan adat. Dari hasil wawancara penulis dengan Nasrul KS.

Datuak Rajo Sutan, seorang panghulu dari suku Sikumbang, niniak mamak dari nagari Lakitan Utara, beliau mengatakan walaupun undang-undang babaliak ka nagari sudah diterapkan, namun niniak mamak masih belum berfungsi sebagai mana mestinya, masih banyak ditemukan niniak mamak yang tidak mengerti tentang seluk beluk adat, bahkan tidak mengerti adat salingka nagari ${ }^{3}$. Dengan kata lain, niniak mamak haruslah mempunyai kualitas yang baik dalam kepemimpinannya, karena pemimpin dihormati karena kualtas kepemimpinannya, bukan karena kedudukannya.

Sulitnya mencari atau memilih niniak mamak yang berpotensi juga menjadi salah satu faktor penyebab pudarnya wibawa niniak mamak di tengah masyarakat Minangkabau. Perkembangan zaman dan pengaruh budaya luar sedikit banyaknya berdampak bagi masyarakat, baik dampak positif maupun dampak negatif yang telah merubah gaya hidup masyarakat Minangkabau. Batas-batas pergaulan, pandangan hidup dan norma-norma yang membentuk kaidah sosial di masyarakat Minang tempo dulu, tanpa disadari telah bergeser. Seiring dengan itu juga timbul benturan-benturan nilai yang menggoyahkan landasan-landasan adat yang kemudian berimbas diberbagai sektor kehidupan baik 
dibidang pendidikan, ekonomi, sampai ke hubungan sosial antara masyarakat sehingga berdampak runtuhnya nilai-nilai moral masyarakat.

Kehidupan dirantau yang tidak terjangkau hukum adat juga mempengaruhi penghargaan terhadap niniak mamak, karena perantau Minang sekarang tidaklah sama dengan hakekat perantau pada tempo dulu. Banyak ditemui perantau Minang yang telah berkeluarga dan menetap di daerah di luar Minangkabau, sehingga pulang ke ranah Minang hanya sebagai pengisi waktu libur dan rekreasi, sehingga wajar saja jika gaya hidup maupun karakter dan sikap mental telah dibentuk oleh budaya dari tempat dimana dia menetap. Apalagi bagi generasi yang memang terlahir dan tumbuh besar di daerah luar Minangkabau, tentu saja sudah sangat jauh dari kata mengenal adat dan budaya orang Minangkabau sehingga membentang jarak yang semakin lebar dengan niniak mamak sebagai pemimpin adat.

Lantas, apakah perkembangan zaman dan pengaruh budaya luar harus dihentikan berkembang di alam Minangkabau untuk mengantisipasi pergeseran nilai-nilai tersebut? Tentu saja itu bukan tindakan yang bijak, karena merupakan pekerjaan yang sia-sia. Selain juga banyak hal positif yang didapat dari dampak perkembangan tersebut, juga mustahil kita bisa menghentikan perkembangan zaman dan pengaruh budaya luar. Pada dasarnya perkembangan zaman dan pengaruh dari budaya luar bukanlah hal yang harus dihindari, yang terpenting adalah berbuat sesuatu dalam mengantisipasi dampak negatif yang ditimbulkan. Untuk itu, tentu saja diperlukan pemimpin yang berkualitas, dalam hal ini adalah niniak mamak sehingga gelar niniak mamak tidak semata hanya sebagai gelar jabatan sebagai pelengkap dalam tatanan adat Minangkabau.

Niniak mamak harus menjadi pemimpin informal dalam menanamkan pandangan hidup dan sikap sebagai orang Minangkabau dalam kehidupan. Niniak mamak juga punya kewajiban untuk mengayomi, melindungi dan mengurus anak kemenakan dan sebaliknya kemenakan juga mempunyai hak untuk diurus oleh niniak mamak. Niniak mamak harus bisa menjaga martabatnya karena gelar datuak yang disandangnya adalah gelar kebesaran pusaka adat dalam suku atau kaumnya. Di sisi lain, niniak mamak juga mempunyai hak untuk di hormati dan di anjung tinggi oleh anak kemenakannya dan kewajiban kaumnya untuk menjaga wibawa niniak mamak di tengah-tengah masyarakat.

\section{E. Kesimpulan}

Dalam kurun waktu yang panjang, pasti ditemui pasang surut kehidupan adat dalam masyarakat karena memang begitulah hukum seleksi alam. Kita dipaksa tunduk dengan kenyataankenyataan sebagai dialektika dan romantika kehidupan. Namun sudah semestinyalah masyarakat Minangkabau melestarikan adat dan ditumbuh kembangkan di tengah-tengah masyarakat sebagai warisan budaya bangsa untuk sekarang dan seterusnya, maka sewajarnyalah kita benahi hal-hal yang berkaitan dengan itu, terutama dalam menjaga wibawa kepemimpinan niniak mamak (panghulu) yang menjadi tiang penyangga dari adat itu sendiri. Agar budaya adat Minangkabau tidak berubah menjadi barang antik pengisi museum sejarah. Adalah tanggung jawab kita bersama untuk mengembalikan gadang basa batuah nya potensi niniak mamak sebagai tiang penyangga berdirinya adat itu sendiri, karena adat adalah benteng terakhir dalam menahan badai pengaruh dari luar (budaya barat).

Semestinyalah masyarakat Minangkabau melestarikan adat terutama dalam menjaga wibawa kepemimpinan niniak mamak (panghulu) sebagai tiang penyangga adat. Ada beberapa hal yang harus disikapi agar martabat dan wibawa niniak mamak sebagai urang nan gadang basa batuah tidak luntur di tengah masyarakat.

\section{Niniak mamak Sebagai Panutan}

Sebagai pemimpin adat, niniak mamak mempunyai kedudukan yang lebih tinggi dibanding jabatan lainnya yang ada dalam masyarakat, karena niniak mamak merupakan tempat sandaran dan tempat bertanya tentang berbagai permasalahan yang dihadapi warga dalam satu nagari. Dalam petitih adat dikatakan:

Bak baringin di tangah koto
Ureknyo tampek baselo
Batangnyo tampek basanda
Dahannyo tampek bagantuang
Daunnyo tampek bataduah kahujanan

Tampek balinduang kapanehan

Nan didahulukan salangkah

Nan ditinggikan sarantiang

Ka pai tampek batanyo

Ka pulang tampek babarito 


\section{GEEAR Jumal sai isulya}

Terjemahan dalam bahasa Indonesia:

Seperti pohon beringin di tengah kota

Akarnya tempat duduk bersila

Batangnya tempat bersandar

Dahannya tempat bergantung

Daunnya tempat berteduh di saat hujan

Tempat berlindung di kala kepanasan

Yang didahulukan selangkah

Yang ditinggikan seranting

Kalau pergi tempat bertanya

Kalau pulang tempat berberita

Niniak mamak sebagai urang nan gadang (orang yang dituakan) dalam kaum, yakni orang yang didahulukan selangkah dan ditinggikan seranting. Niniak mamak merupakan baringin di tangah koto $^{4}$ bagi masyarakatnya, sudah menjadi tanggung jawab niniak mamak untuk menjaga dan membina anak kemenakannya.

Arus perubahan zaman sangat berpengaruh terhadap kehidupan sosial masyarakat. Kehidupan sosial yang dulu berdasarkan kebersamaan atau musyawarah tergeser menjadi individualis dan konsumeritis, lebih condong kepada memelihara kepentingan diri sendiri dari pada anggota masyarakatnya. Di sinilah pentingnya peranan niniak mamak sebagai sosok panutan dalam masyarakat untuk menjaga tatanan adat pada kehidupan masyarakat Minangkabau. Dengan adanya niniak mamak sebagai sosok panutan dalam masyarakat, masyarakat tidak akan mudah terpengaruhi oleh efek negatif dari budaya luar. Niniak mamak sebagai contoh tauladan bagi masyarakatnya, mengarahkan masyarakatnya ke arah yang lebih baik, membina dan menjaga sekaligus bisa jadi tempat sandaran bagi anak kemenakannya.

\section{Komunikasi Niniak mamak Dengan Anak Kemenakan}

Komunikasi merupakan hal yang sangat penting dalam interaksi sosial. Perubahan perilaku sosial masyarakat yang semakin mengarah individualisme menyebabkan semakin kurangnya komunikasi antara pemimpin dengan yang dipimpin. Hubungan niniak mamak dengan masyarakat kaum yang dulu sangat kental, perlahan mulai berangsur hilang. Niniak mamak tidak lagi difungsikan sebagai pai tampek batanyo, pulang tampek babarito (pergi tempat bertanya, pulang tempat berberita) yaitu sebagai pembimbing bagi anak kemenakannya.
Oleh sebab itu, komunikasi antara niniak mamak dengan masyarakat penting dijaga untuk mempertahankan wibawa kepemimpinan niniak mamak di Minangkabau. Karena tanpa adanya komunikasi, mustahil pemimpin bisa membimbing yang dipimpinnya. Dalam menjalin komunikasi antara niniak mamak dan anak kemenakan dalam masyarakat Minangkabau, anak kemenakanlah yang harus terlebih dahulu bertanya dan meminta pendapat kepada niniak mamak ketika ada permasalahan yang dihadapi, baru setelah itu niniak mamak mencarikan jalan keluar untuk permasalahannya. Namun bukan berarti setiap permasalahan yang terjadi didalam masyarakatnya harus diselesaikan oleh niniak mamak, tetap ada peraturan seperti falsafah Minangkabau yang berbunyi "bajanjang naiak, batanggo turun"s. Kemenakan harus terlebih dahulu meminta pendapat kepada mamak ${ }^{6}$, kalau mamak juga sudah tidak sanggup untuk memberikan solusi, barulah mamak meminta pendapat kepada niniak mamak. Sesuai dengan falsafah Minangkabau yang berbunyi "anak barajo ka mamak, mamak ba rajo ka panghulu" . Intinya selalu menjaga komunikasi antara niniak mamak dengan anak kemenakan, selalu memberikan informasi sehingga niniak mamak mengetahui segala sesuatu yang terjadi dalam masyarakat kaumnya.

\section{Arif dan Bijaksana}

Dalam kelembutan ada ketegasan, sedangkan dalam sikap yang tegas ada kelembutan, demikianlah niniak mamak dalam kepemimpinannya di Minangkabau. Ungkapan ini merupakan penggambaran dari kearifan dan kebijaksanaan niniak mamak dalam kehidupan masyarakat Minangkabau. Niniak mamak hendaklah bersifat arif dan bijaksana dalam mengambil tindakan. Arif dan bijaksana pada hakekatnya mampu bertindak sesuai dengan norma-norma yang hidup dalam masyarakat baik norma hukum, norma keagamaan, kebiasaan-kebiasaan maupun kesusilaan dengan memperhatikan situasi dan kondisi pada saat itu, serta mampu memperhitungkan akibat dari tindakannya.

Niniak mamak harus arif dan bijaksana dalam menyikapi kuatnya arus budaya luar yang dapat mempengaruhi pola pikir masyarakat. Pada dasarnya perkembangan zaman dan pengaruh dari budaya luar bukanlah hal yang harus dihindari, yang terpenting adalah berbuat sesuatu dalam mengantisipasi dampak negatif yang ditimbulkan. Niniak mamak menjadi pemimpin informal dalam menanamkan pandangan 
hidup dan sikap sebagai orang Minangkabau dalam kehidupan sehingga bisa terhindar dari dampak buruk arus perkembangan zaman. Perilaku yang arif dan bijaksana mendorong terbentuknya pribadi yang berwawasan luas, mempunyai tenggang rasa yang tinggi, bersikap hati-hati, sabar dan santun.

\section{Catatan Akhir:}

${ }^{1}$ Barih balabeh artinya baris/garis ketentuan adat yang berlaku dalam tatanan suatuwilayah

${ }^{2}$ Nagariadalah Bahasa Minangkabau yang berarti wilayah

${ }^{3}$ Adat salingka nagari (adat seputar negeri), dengan artian ; aturan dalam suatu negeri dengan negeri yang lain tidaklah sama

${ }^{4}$ Baringin di tangah koto berarti pohon beringin di tengah kota

${ }^{5}$ Bajanjang naiak batanggo turun merupakan falsafah Minangkabau yang berarti prosedur yang dilalui harus bertingkat dari yang terendah baru naik sampai yang paling tinggi.

${ }^{6}$ Mamak adalah saudara laki-laki dari ibu, atau keluarga laki-laki dari garis keturunanibu.

${ }^{7}$ Anak ba rajo ka mamak, mamak ba rajo ka panghulu artinya anak kemenakanmeminta pendapat kepada mamak, mamak minta pendapat ke niniak mamak.

\section{KEPUSTAKAAN}

Dt. Sanggono Diradjo, Ibrahim, Tambo Alam Minangkabau : Tatanan Adat Warisan
Nenek Moyang Orang Minang, Bukittinggi : Kristal Multimedia, 2009.

KAN, Nagari Kambang, Monografi Adat Nagari Kambang, Kambang : KAN, 2007.

Kamus Besar Bahasa Indonesia, Jakarta : Balai Pustaka,1988.

Navis, A.A, Alam Terkembang Jadi Guru : Adat Dan Kebudayaan Minangkabau, Jakarta : PT Pustika Grafitipers, 1984.

Richard L. Huges, Robert C. Ginnet, Gordon J. Curphy. Leadership : Enhancing the Lessons of Experience. 7th ed. Terjemahan Putri Iva Izzati. Jakarta: Salemba Humanika, 2012.

Rusmin Tumanggor, Kholis Ridho, H. Nurrochim. IImu Sosial dan Budaya Dasar. Ed 1. Jakarta : Kencana, 2010.

\section{Narasumber:}

KS. Dt. Rajo Sutan, Nasrul (61), niniak mamak di kenagarian Lakitan. Pasar

Baru Kenagarian Lakitan Utara, Pesisir Selatan, Sumbar. 